\title{
Valor de tarefas de aprendizagem para universitários de cursos noturnos
}

\author{
Valor de tarefas de aprendizagem
}

\author{
Valdete Maria Ruiz
}

\begin{abstract}
Resumo
Objetivou-se analisar a ocorrência de diferenças na variável motivacional valor da tarefa entre estudantes de primeiro e último ano de três cursos do período noturno, em um centro universitário privado. Participaram 120 estudantes, sendo 20 do primeiro e 20 do quarto ano dos cursos de Administração, Ciência da Computação e Educação Física. Os dados foram obtidos por meio da sub-escala Valor da Tarefa do questionário Motivação e Atitudes Acadêmicas, elaborado a partir da tradução e adaptação do instrumento MSLQ. A análise de variância indicou diferença significante a favor do grupo do quarto ano de Ciência da Computação em relação aos demais $(p \leq 0,05)$. Os resultados são discutidos com base no modelo expectativa-valor da motivação, sugerindo que o componente valor ou interesse intrínseco foi o principal responsável pela redução do valor que esses participantes atribuíram às suas tarefas de aprendizagem.

Palavras-chave: Motivação, Ensino Superior, Atitudes.
\end{abstract}

\section{Value of learning tasks for university students of nocturnal courses}

\begin{abstract}
The objective was to verify the occurrence of differences in motivational variable task value between beginners and students of the last year of three courses of the nocturnal period of one private universitary center. It counted with the participation of 120 students, being 20 of the first and 20 of the fourth year of de courses of Administration, Computer Science and Physical Education. The data were obtained through the questionnaire Academic Motivation and Attitudes, elaborated from the translation and adaptation of the instrument MSLQ. The analyses of the variance indicated significant difference at minor in the group of the fourth year of Computer Science in relation to the others $(p \leq 0,05)$. The results are discussed based on the motivation expectancy-value model, suggesting that the component value or intrinsic interest was the main responsible for the reduction of the value that these participants attributed to their learning tasks.
\end{abstract}

Key words: Motivation, Higher Education, Attitudes.

\section{Valor de las tareas de aprendizaje para universitarios de cursos nocturnos}

\begin{abstract}
Resumen
El objetivo fue analizar la presencia de diferencias en la variable relacionada a la motivación valor de la tarea entre estudiantes del primero y último año de tres cursos del turno nocturno, en una universidad privada. Participaron 120 estudiantes, siendo 20 del primero y 20 del cuarto año de los cursos de Administración, Ciencias de la Computación y Educación Física. Los datos fueron obtenidos por medio de la sub-escala Valor de la Tarea del cuestionario Motivación y Actitudes Académicas, elaborado a partir de la traducción y adaptación del instrumento MSLQ. El análisis de variancia indicó diferencia significativa a favor del grupo del cuarto año de Ciencias de la Computación en relación a los demás $(p \leq 0,05)$. Los resultados son discutidos con base en el modelo expectativa-valor de la motivación, sugiriendo que el componente valor o interés intrínseco fue el principal responsable por la reducción del valor que esos participantes atribuyeron a sus tareas y aprendizaje.
\end{abstract}

Palabras clave: Motivación, Enseñanza Superior, Actitudes. 


\section{Introdução}

O valor que estudantes atribuem às suas tarefas de aprendizagem é uma variável que tem grande influência na sua motivação e, conseqüentemente, no processo de ensino-aprendizagem (Ruiz, 2005a).

Brophy (1998) explica que, sob o ponto de vista afetivo, o aluno que está engajado numa tarefa que valoriza positivamente sente prazer, alegria, e o próprio envolvimento nessa tarefa é uma recompensa para ele. Cognitivamente, tem uma concentração "relaxada" nos processos envolvidos na realização da mesma. Está metacognitivamente consciente sobre o que a tarefa requer e sobre como responder a ela, além de manter o foco no conteúdo acadêmico durante 0 processo de aprendizagem e na qualidade do produto, por ocasião do desempenho.

Em contrapartida, o mesmo autor afirma que quando o aluno está engajado numa tarefa que valoriza de forma negativa, costuma reagir aos processos relacionados à própria tarefa com sentimentos de raiva ou medo. Não gosta da tarefa, que tem um efeito punitivo para ele. Em decorrência, tende a se tornar alienado ou resistente e a não desejar adquirir o conhecimento ou habilidade inerentes a ela. Sob o ponto de vista cognitivo, para esse estudante, o foco da tarefa é "invadido" pelo ressentimento de se sentir coagido a fazer atividades pouco prazerosas ou sem objetivo. Como resultado, experimenta um conflito entre o que a tarefa representa e seu próprio autoconceito, papel do gênero, identificação e outros fatores ligados ao self. Além disso, antecipa as conseqüências indesejáveis do envolvimento com tal tarefa.

Como uma variável motivacional, o valor da tarefa tem sido conceptualizado de diferentes formas a depender do modelo teórico adotado pelo autor/pesquisador e está presente na literatura psicológica desde os anos 30 do último século, a partir das contribuições de Lewin e de Atkinson (Bzuneck, 2001a; Weiner, 2000).

As teorias expectativa-valor, sobretudo o modelo derivado do trabalho de Eccles, Wigfield e seus colaboradores (Eccles \& Wigfield, 2002; Wigfield \& Eccles, 1992; Wigfield \& Eccles, 2000), constituem um dos enfoques teóricos que, segundo Pintrich \& Schunk (2002), têm oferecido suporte empírico mais forte para se estudar a motivação em ambientes educacionais. Por isso foi privilegiado nesse estudo.

Neste modelo, esses estudiosos utilizam o termo valor subjetivo da tarefa, conceituando-o com base nos quatro componentes descritos a seguir.

O primeiro deles é o valor de obtenção (ou simplesmente importância), e está diretamente relacionado à extensão em que as tarefas de aprendizagem levam o indivíduo a confirmar ou não aspectos proeminentes ou centrais de seu auto-esquema, intimamente ligados a suas metas, julgamentos de competência, percepções sobre dificuldades das tarefas e memórias afetivas. Esses, por sua vez, são influenciados por seus processos cognitivos (percepções sobre o ambiente social e interpretações e atribuições para eventos passados) e pelo ambiente social, incluindo seu padrão cultural, socializadores de comportamento, eventos e desempenhos passados.

O segundo componente do valor da tarefa - o valor intrínseco (ou interesse intrínseco) - é definido como o sentimento de prazer que os estudantes experimentam quando estão fazendo uma tarefa ou seu interesse subjetivo no conteúdo da mesma. Está, portanto, muito mais relacionado ao significado de fazer uma tarefa do que aos seus objetivos finais. Por isso, quando o valor intrínseco é alto, o aluno tende a se engajar mais na tarefa, a persistir mais e a continuar intrinsecamente motivado por ela.

Ainda de acordo com essa versão do modelo expectativa-valor da motivação, o valor de utilidade é o terceiro componente do valor da tarefa, sendo entendido como a possibilidade de utilização da tarefa pelos estudantes em termos de metas futuras, incluindo suas metas de carreira. Esse componente pode explicar, por exemplo, porque alguns alunos podem não ter muito interesse intrínseco por atividades de determinadas disciplinas do currículo mas, posto que desejam se graduar e obter seu diploma, o curso pode ter grande valor de utilidade para eles.

Por fim, o quarto componente do valor da tarefa presente neste modelo da motivação é a crença sobre o custo relacionado ao envolvimento na tarefa. É definido pelos aspectos negativos do envolvimento na tarefa em si, tendo-se em vista que quando uma pessoa decide se engajar numa atividade não pode se engajar em outra, ao mesmo tempo. Essa decisão tem custos que incluem a quantidade de esforço requerido pela tarefa, tanto quanto a antecipação de estados emocionais como a ansiedade pelo desempenho ou o medo do fracasso.

Estudos recentes baseados no modelo de Eccles e Wigfield (2002) sugerem que as crenças sobre o valor de obtenção, intrínseco e de utilidade estão intimamente ligadas à escolha de comportamentos como a decisão de fazer determinados cursos ou seguir determinadas carreiras no futuro. Investigando tais constructos em crianças, adolescentes e adultos, estes estudos também indicam que a crenças sobre valor da tarefa têm um domínio específico (aplicam-se a áreas de conhecimento específicas ou tarefas/atividades afins) e, ainda, que tendem a apresentar um declínio com a idade, sendo influenciadas por fatores socioculturais e pelo gênero 
(Eccles \& Wigfield, 2002; Eklof, 2006; Legault, GreenDemers \& Pelletier, 2006; Watt, 2006).

Em estudo com universitários de cursos noturnos, Ruiz (2005a) verificou que a variável valor da tarefa foi a que obteve maior escore em relação a outras consideradas como componentes da motivação para a aprendizagem. Todavia, os escores da variável valor da tarefa apresentaram decréscimos quando comparados no conjunto dos ingressantes e dos concluintes. Também apresentaram diferenças entre os cursos pesquisados.

Sendo assim, o presente estudo se propôs a analisar, mais apuradamente, as diferenças verificadas nos dados anteriormente obtidos junto à mesma população. Seus objetivos específicos foram verificar a ocorrência de diferenças entre estudantes de três cursos noturnos (Administração, Educação Física e Ciência da Computação) e estudantes no início e no final de seus cursos quanto à variável motivacional valor da tarefa.

\section{Método}

\section{Participantes}

Foram participantes 120 estudantes de um centro universitário privado, localizado no interior do Estado de São Paulo. Destes, 20 eram alunos do primeiro e 20 do quarto (último) ano de cursos noturnos de Administração, Educação Física e Ciência de Computação.

No $1^{\circ}$ ano de Educação Física (EF), 10 alunos eram do gênero masculino e 10 do feminino, com idade entre $17 \mathrm{e}$ 30 anos, predominando a faixa entre 17 a 20 anos e os solteiros (18), sendo que 9 trabalhavam em período integral, 4 em meio período e 7 não trabalhavam. Os alunos de $4^{\circ}$.ano também eram metade de cada gênero. Tinham idades de 17 a mais de 40 anos, predominando a faixa entre 21 e 24 anos (17), 18 eram solteiros, 13 trabalhavam em período integral, dois não trabalhavam e os demais com menor tempo de trabalho diário. Os do $1^{\circ}$ ano declararam estudar de duas a 5 horas semanais (7) ou de uma a duas horas (5), sendo que 5 não tinham hora para tal atividade e 3 dedicavam a ela de 5 a 8 horas por semana. Os do último ano estudavam de uma a duas horas (7) ou de 5 até 8 horas (7), os demais com variações.

Os participantes do $1^{\circ}$ ano de Administração (AD) foram 10 do gênero masculino e 10 do feminino, com idade entre 17 a 30 anos e predomínio das faixas entre 17 a 20 anos (15) e 21 a 24 anos (4). Destes, 19 eram solteiros, 14 trabalhavam em período integral e 5 não trabalhavam. No $4^{\circ}$ ano, também foram metade do gênero masculino e metade do feminino, com idades entre 17 e 40 anos e maior freqüência nas faixas entre 21 a 24 anos (13) e 25 a 30 anos (4). A maioria era de solteiros (18) e trabalhava em período integral (18). No $1^{\circ}$ ano, 10 declararam estudar entre uma a duas horas por semana, 7 de duas até 5 horas e 3 declararam não estudar fora da sala de aula. No $4^{\circ}$ ano, 10 não dedicavam nenhuma hora extra-classe aos estudos, 8 dedicavam de uma a duas horas e 2 de duas a 5 horas.

Em Ciência da Computação (CC), os alunos do $1^{\circ}$ ano foram 13 do gênero masculino e 7 do feminino, sendo 9 na faixa de 17 a 20 anos, 8 entre 21 e 24 anos e 3 na faixa dos 25 aos 30 anos. Todos eram solteiros, 13 trabalhavam em período integral, 2 em meio período, 4 não trabalhavam e um exercia trabalhos eventuais. Os do $4^{\circ}$ ano foram 18 do gênero masculino e 2 do feminino. Tinham idade entre 17 e 30 anos, predominando os que se situaram na faixa de 21 a 24 anos (15). Todos também eram solteiros e apenas um não exercia trabalho remunerado em período integral. Quanto ao tempo de estudo, no $1^{\circ}$ ano, a faixa predominante foi a de uma a duas horas semanais (8), sendo que 5 se situaram na faixa de duas a cinco horas, 2 na faixa de cinco a 8 horas e 5 não estudavam. № $4^{\circ}$ ano, predominaram os que não estudavam (8), seguidos pelos que estudavam de uma a 2 horas semanais (6), os que estudavam de cinco a oito horas (3) e os demais em outras faixas.

\section{Instrumento}

Para a coleta de dados foi utilizado o questionário Motivação e Atitudes Acadêmicas, o qual foi traduzido e adaptado por Ruiz (2005a) da seção motivacional do instrumento MSLQ - Motivated Strategies for Learning Questionnaire, que consiste em 31 itens, alocados em três escalas gerais e seis sub-escalas baseadas num modelo cognitivista social geral e propõe três grandes constructos sobre a motivação: expectativa, valor e afeto. Os componentes relativos à expectativa se referem aos sentimentos e crenças dos estudantes de que podem realizar uma tarefa acadêmica. São acessados por duas sub-escalas: Percepção de Auto-Eficácia e Crenças sobre Controle da Aprendizagem. Os componentes do valor focalizam as razões pelas quais os estudantes se engajam numa tarefa acadêmica e são avaliadas por três subescalas: Orientação para a Meta Intrínseca (foco na aprendizagem e domínio), Orientação para a Meta Extrínseca (foco em notas e aprovação de outros) e Valor da Tarefa (julgamento sobre o quanto os conteúdos do curso são interessantes, úteis e importantes para 0 estudante). $O$ afeto, terceiro constructo motivacional presente no MSLQ, é definido operacionalmente em termos de respostas à escala Ansiedade frente a Provas, que focaliza a preocupação de estudantes ao fazer exames ou avaliações (Pintrich, Smith, Garcia \& Mckeachie, 1991).

Segundo seus autores, o MSLQ tem uma fidedignidade relativamente boa em termos de consistência interna. Os pressupostos teóricos gerais e as escalas que os medem 
mostram-se válidos, dados os resultados de duas análises fatoriais confirmatórias que apresentam. As seis subescalas motivacionais representam uma coerência conceitual e uma estrutura validada empiricamente para avaliar os três componentes da motivação de universitários (expectativa, valor e afeto), que assumem ser fatores distintos. Quanto à sua validade preditiva, consideram que as escalas motivacionais foram relacionadas com desempenho acadêmico na direção esperada (Pintrich, Smith, Garcia \& McKeachie, 1993; Garcia \& Pintrich, 1995).

Dado seu objetivo, o presente estudo utilizou apenas os dados da sub-escala Valor da Tarefa do MSLQ, constituída pelos seguintes itens: (1) Penso que serei capaz de usar o que aprendo em uma disciplina em outras; (2) É importante para mim aprender a matéria de todas as disciplinas; (3) Estou muito interessado na área de conteúdo do curso; (4) Penso que as matérias das várias disciplinas que estou cursando são úteis para que eu aprenda; (5) Gosto das disciplinas que estou cursando; (6) Entender os assuntos das disciplinas é muito importante para mim.

Além das seis questões relativas à avaliação do valor da tarefa e das demais variáveis da motivação para a aprendizagem contidas no MSLQ, o questionário Motivação e Atitudes Acadêmicas também contém outras cinco para a caracterização da amostra, além de orientações sobre a finalidade do estudo, sobre como responder ao questionário e um Termo de Consentimento Livre e Esclarecido que os participantes assinaram.

Cumpre notar que o instrumento original (MSLQ) se propõe a avaliar variáveis motivacionais em determinadas disciplinas de um curso superior, mas a adaptação feita para utilização nessa pesquisa visou avaliá-las em todas as disciplinas dos cursos selecionados.

\section{Procedimento}

Após a obtenção de autorização da instituição de ensino pesquisada e do Comitê de Ética em Pesquisa com Seres Humanos da PUC-Campinas (processo no. 117/04), o instrumento foi aplicado coletivamente pela Autora em dias normais de aula, nas próprias salas dos participantes, no mês de maio de 2004. Em média, o tempo de aplicação do questionário completo, em cada turma, foi de 20 minutos.

Para a análise de dados do presente estudo, dos 185 questionários válidos obtidos, foram sorteados 20 de cada ano $\left(1^{2}\right.$ e $\left.4^{\circ}\right)$ dos três cursos pesquisados, por meio de uma tabela de números aleatórios (Spiegel, 1976). Isso a fim de totalizar o número de questionários que permitisse atender aos objetivos do estudo e igualar o número de participantes por número e área.

Também optou-se por sortear 10 questionários de participantes do gênero masculino e 10 do feminino em cada turma, a fim de homogeneizar essa variável. Entretanto, isso não foi possível no caso do curso de CC, devido à composição das turmas do $1^{\circ}$ e $4^{\circ}$. ano. Sendo assim, nesse curso, a amostra foi constituída com maior número de estudantes do gênero masculino. Nessas circunstâncias, desistiu-se da análise estatística dessa variável.

\section{Resultados}

As respostas de cada participante na sub-escala Valor da Tarefa foram computadas e tabuladas por total de turma. Considerando-se que, de acordo com o instrumento utilizado, a média máxima é 7,00 , os participantes do estudo, em seu conjunto, obtiveram média 5,72, ou seja, atingiram cerca de $82 \%$ do total da sub-escala Valor da Tarefa. Porém, a média geral das turmas no último ano $(5,57)$ foi menor que no $1^{\circ}$ ano $(5,88)$. Estas médias significam, respectivamente, $79 \%$ e $84 \%$ do total da escala. Também ocorreram diferenças entre as médias de cada curso e entre o $1^{\circ}$. e o $4^{\circ}$. ano de cada um.

Dos três cursos, o de EF foi o que obteve a melhor média geral $(5,93)$ e o único que teve um aumento da média do $1^{\circ}$. $(5,89)$ para $\circ 4^{\circ}$. ano. $(5,97)$. Por outro lado, o de CC foi o que apresentou menor média $(5,42)$ no total de alunos, sendo de 5,88 no $1^{\underline{a}}$ ano e de 4,96 no $4^{\underline{a}}$ ano. Seus resultados foram mais próximos aos de $A D$ e, como este último, apresentou um decréscimo no valor da média no $4^{\circ}$. ano em relação ao $1^{\circ}$. Contudo, esse decréscimo foi maior em CC. AD teve média geral de 5,83 , sendo 5,86 no $1^{\text {a }}$ ano e 5,79 no $4^{\underline{a}}$ ano.

A fim de verificar a significância das diferenças encontradas e atender aos objetivos específicos desse estudo, os resultados médios obtidos em cada grupo foram, posteriormente, tratados estatisticamente pelo método de Análise de Variância não Paramétrica (Wilcoxon \& Wilcox, 1964). Esses resultados são expressos na Tabela 1, seguindo o modelo proposto pelos autores.

Para as comparações entre os grupos de participantes de $1^{\circ}$ e $4^{\circ}$ anos dos três cursos, considerou-se $n=20 ; k=$ $3 ; p \leq 0,05$, sendo a diferença crítica de 210. A hipótese de igualdade foi expressa como $H_{0}: A D=C C=E F$ e a hipótese alternativa como $H_{a}: A D \neq C C \neq E F$. 
Tabela 1. Análise de Variância de Wilcox e Wilcoxon (1964) do Valor da Tarefa por ano e curso

\begin{tabular}{|c|c|c|c|c|c|c|c|}
\hline \multirow{2}{*}{$\begin{array}{l}\text { Anos } \\
\text { Cursos }\end{array}$} & \multicolumn{3}{|c|}{$1^{\circ}$ ano } & \multicolumn{4}{|c|}{4 ano } \\
\hline & $\mathrm{AD}$ & $\mathrm{EF}$ & $\mathrm{CC}$ & & $\mathrm{CC}$ & $\mathrm{AD}$ & $\mathrm{EF}$ \\
\hline & 625,0 & 624,0 & 581,0 & & 813,0 & 542,0 & 475,0 \\
\hline $\mathrm{AD}$ & & & & CC & & & \\
\hline 625,0 & & & & 813,0 & & & \\
\hline $\mathrm{EF}$ & & & & $A D$ & & & \\
\hline 624,0 & 1,0 & & & 542,0 & $271,0^{(*)}$ & & \\
\hline $\mathrm{CC}$ & & & & EF & & & \\
\hline 581,0 & 44,0 & 43,0 & & 475,0 & $338,0^{(*)}$ & 67,0 & \\
\hline $\mathrm{n}=20$ & & & ifi & & & & \\
\hline
\end{tabular}

A inspeção da Tabela 1 permite verificar que as diferenças entre os três cursos em seus primeiros anos são muito pequenas. No caso dos cursos de $A D$ e EF a diferença é insignificante $\left(d_{0}=1,0\right)$ e, no caso das diferenças entre o de $\mathrm{CC}$ e os outros dois, um pouco maior (com $A D d_{0}=44,0$ e com EF $d_{0}=43,0$ ). Ainda assim, essas diferenças estão bem abaixo da $d_{c}$. Constata-se assim que, ao ingressarem no $1^{\circ}$ ano, os alunos dos três cursos são praticamente iguais quanto ao valor que atribuem às suas tarefas de aprendizagem.

Não obstante, no último ano, ocorreram maiores diferenças entre eles. Estas se deram especialmente entre os cursos de CC e EF $\left(d_{0}=338,0\right)$ e CC e AD $\left(d_{0}=271,0\right)$, tendo ambas alcançado significância, sob o ponto de vista estatístico. De fato, verifica-se que os estudantes de CC evidenciaram uma acentuada tendência de declínio do valor da tarefa do $1^{\circ}$ para o $4^{\circ}$ ano do curso, o que indica que, nesse aspecto, demonstraram um padrão motivacional bastante diferenciado em relação aos estudantes dos outros dois cursos, dado que merece ser especialmente discutido.

Analisando-se as respostas do total dos participantes, tem-se que a maior média $(6,16)$ ocorreu na questão sobre a importância de aprender a matéria de todas as disciplinas do curso e a menor $(5,01)$ na questão sobre seu pensamento de que serão capazes de usar o que aprendem em uma disciplina nas outras. O mesmo aconteceu no total dos três cursos em seus primeiros anos, onde a maior média $(6,43)$ foi obtida na primeira questão citada e a menor $(4,88)$ na segunda. Já no total dos cursos no último ano, enquanto o maior escore $(5,88)$ também ocorreu na questão sobre a importância de aprender a matéria de todas as disciplinas, o menor $(5,05)$ foi obtido em outra: a relativa ao gosto dos participantes pelos assuntos das disciplinas do curso.

No curso de EF, as maiores médias $(6,43)$ foram verificadas nas questões em que os participantes, em seu conjunto, responderam estar muito interessados na área de conteúdo do curso e na importância de entender os assuntos das disciplinas. No $1^{\circ}$. ano, a primeira delas teve maior escore $(6,60)$, enquanto no $4^{\circ}$. ano foi a segunda que obteve maior média $(6,35)$. Por outro lado, as menores médias, seja no total de alunos $(5,15)$, seja no $1^{\circ}$. ano $(4,70)$ e no $4^{\circ}$. $(5,60)$ ocorreram na questão relacionada ao pensamento dos participantes sobre poderem usar o que aprendem em uma disciplina nas demais.

Em AD, o maior escore total $(6,45)$ foi verificado na questão ligada à importância de aprender a matéria de todas as disciplinas. O mesmo ocorreu na turma do $4^{\circ}$. ano, onde o índice dessa questão foi de 6,50. Todavia, no $1^{\circ}$. ano do curso, a maior média $(6,50)$ foi encontrada na questão relacionada à importância de entender os assuntos das disciplinas. Neste curso, tanto no total dos participantes quanto no $1^{\circ}$. ano, os menores escores incidiram na questão sobre o pensamento dos alunos a respeito de poderem usar o que aprendem em uma disciplina em outra $\left(4,98\right.$ no total e 4,55 no $1^{\circ}$. ano). Já no $4^{\circ}$. ano, o menor índice $(5,25)$ ocorreu na questão sobre o gosto pelos assuntos das disciplinas.

No curso de CC, a questão sobre a importância de aprender a matéria de todas as disciplinas também foi alcançou maior média no conjunto dos alunos $(5,88)$. O 
mesmo ocorreu no $1^{\circ}$. ano, onde a média dessa questão foi um pouco maior $(6,50)$. Contudo, no $4^{\circ}$. ano, foi a questão sobre o interesse na área de conteúdo do curso que alcançou maior média (5,50). Quanto aos menores escores de CC, dois deles (4,78 no total e 4,05 no $4^{\circ}$ ano) ocorreram na questão relacionada ao gosto dos alunos pelas disciplinas do curso. O outro $\left(5,40\right.$ no $1^{\circ}$. ano) ocorreu na questão sobre o pensamento dos estudantes de serem capazes de usar o que aprendem em uma disciplina em outras.

Tendo em vista os dados anteriores sobre as questões da pesquisa, verifica-se, em síntese, que a maioria dos grupos de participantes obteve maiores escores na questão relacionada à importância de aprender a matéria de todas as disciplinas. Exceção a isso ocorreu no $1^{\circ}$. ano de $A D$, no $4^{\circ}$. de $C C$ e nos três grupos do curso de EF que, mais uma vez, se apresenta como o mais diferenciado dos demais.

Por outro lado, esses dados indicam que a maioria dos grupos atribuiu menores índices de avaliação à pergunta relativa ao pensamento sobre sua capacidade de usar 0 que aprendem numa disciplina em outra. Entretanto, na totalidade dos grupos de $4^{\circ}$. ano e, em especial no $4^{\circ}$. de $A D$ e no $4^{\circ}$ de $C C$, os menores escores foram encontrados na questão sobre o gosto dos participantes pelas disciplinas de sus cursos.

Com isso também se verifica que os dados qualitativos dos grupos de $A D$ e $C C$ são mais semelhantes, principalmente no $4^{\circ}$. ano.

\section{Discussão}

De acordo com os pressupostos teóricos do instrumento utilizado, a sub-escala Valor da Tarefa diz respeito à percepção e avaliação dos estudantes sobre o quanto as matérias escolares (e as tarefas a elas ligadas) são interessantes, importantes e úteis (Pintrich \& cols., 1991).

Sendo assim, os resultados obtidos com o conjunto dos participantes mostram que sua motivação está fundada, de maneira especial, nos três primeiros componentes do valor da tarefa propostos por Eccles e Wigfield (Eccles \& Wigfield, 2002; Wigfield \& Eccles, 1992, 2000): o valor de obtenção (importância), o valor intrínseco (interesse intrínseco) e o valor de utilidade.

Esses resultados são superiores aos obtidos em outros estudos que utilizaram o mesmo instrumento com diferentes populações de universitários (Kivinen, 2003; Pintrich \& cols., 1991; Powdril, Just, Garcia \& Amador, 1997) - o que pode ser reflexo de diferenças socioculturais, entre elas o nível socioeconômico e a formação educacional anterior.

Dado que esses são os primeiros fatores que exercem influência sobre a motivação de universitários, conforme ilustra o modelo apresentado por Dembo (2000), e que são alguns dos que estão a merecer maior número de estudos e pesquisas sobre a motivação em contextos educacionais (Linnenbrink \& Pintrich, 2002; Ruiz, 2005b), estudá-los em diferentes grupos de universitários brasileiros é a primeira sugestão que decorre do presente trabalho.

A propósito dos resultados superiores da população pesquisada em relação às demais citadas, também vale relembrar os resultados do estudo de Ruiz (2005a), mediante os quais se verificou que, para os mesmos participantes, o valor da tarefa foi a variável que obteve maior índice, comparado ao de outros componentes da motivação (orientação para a meta intrínseca, orientação para a meta extrínseca, crenças sobre controle da aprendizagem, auto-eficácia para aprendizagem e desempenho e ansiedade a provas).

Sendo assim, pode-se concluir que, sob o ponto de vista motivacional, esta variável é prioritária para os participantes, talvez a ponto do valor que atribuíram aos seus cursos ter prevalecido sobre fatores eventualmente mais negativos ou limitadores ligados à sua condição de estudantes-trabalhadores que freqüentam cursos noturnos. Merece, pois, ser capitalizada pela instituição de ensino pesquisada e por outras que tenham alunos nas mesmas condições, destacando-se, principalmente, a importância de aprenderem as matérias de todas as disciplinas dos cursos, sem privilégio de nenhuma sobre as outras. Isto porque, esta foi a questão que obteve as maiores médias, tanto no total de alunos, quanto nas três turmas de ingressantes.

Porém, tendo-se em vista que as menores médias desses dois grupos incidiram na pergunta relativa à percepção dos participantes sobre serem capazes de usar o que aprendem em uma disciplina nas outras, é recomendável que se cuide de fazer com que percebam melhor a relação existente entre os conteúdos das diferentes disciplinas, ou seja, sua interdisciplinaridade. Sugere-se que este aspecto seja melhor considerado no planejamento educacional dos cursos e priorizado pelos docentes, em sala de aula.

Outro ponto importante a ser discutido é que, independentemente da área do conhecimento ou do curso, os resultados indicam homogeneidade entre os ingressantes quanto ao valor da tarefa, ou seja, todos eles entraram na faculdade com o mesmo grau de interesse, atribuindo a mesma utilidade e, sobretudo, a mesma importância de aprender os conteúdos das diferentes disciplinas.

Entretanto, verificou-se uma redução do valor da tarefa no $4^{\circ}$ ano em dois dos cursos pesquisados: AD e CC. Este dado leva a crer que as mudanças ocorridas na variável decorreram de fatores relacionados aos próprios cursos, incluindo seu planejamento educacional, currículo, ambientes de sala de aula e professores, o que é bastante 
plausível, tendo-se em vista outros estudos registrados na literatura (Ames, 1992; Pintrich \& Schunk, 2002; Ruiz, 2005b).

Nos casos dos cursos de AD e CC é importante considerar que estudos de Eccles, Wigfield e seus colegas (Eccles \& Wigfield, 2002; Roeser, Eccles \& Sameroff, 2000; Wigfield \& Eccles, 1992, 2000) verificaram uma tendência de diminuição dos componentes do valor da tarefa conforme a área de conhecimento, atividade de aprendizagem e a idade. Em matemática e ciências, por exemplo - áreas a que está relacionado o curso de CC e, em menor grau, o de AD - essa diminuição tende a ser maior. Portanto, a redução nos índices no $4^{\circ}$. ano destes cursos pode ser devida a esses aspectos. Resta saber se essa redução foi pontual e específica nesse período letivo destes cursos, ou se ocorreu de forma gradativa do primeiro ao último período dos mesmos. Esse ponto, entretanto, não pode ser aqui esclarecido, dada a natureza transversal da pesquisa. Sendo assim, sugerem-se novos estudos com esse objetivo, mesmo porque a redução foi acompanhada por uma diminuição do gosto desses participantes pelos assuntos das disciplinas de seus cursos.

Quanto aos resultados do $4^{\circ}$. ano dos três cursos, é preciso discutir, mais especificamente, os do curso de CC, já que esses foram estatisticamente diferentes dos demais.

Com base na conceituação do valor de obtenção, pode-se dizer que esse grupo de participantes de CC deu menor importância a suas tarefas de aprendizagem porque estas não iam ao encontro de fatores centrais de seu autoesquema. Isto equivaleria a afirmar que, pelo fato da grande maioria deles ser de estudantes do gênero masculino, todos solteiros (provavelmente sem maiores responsabilidades familiares), pouco mais velhos ao ingressar na faculdade, além de trabalharem mais que os colegas, estas características de seu auto-esquema (além de outras que não foram aqui identificadas) podem não os ter levado a dar importância prioritária a tarefas de aprendizagem, mas a outras (como as ligadas ao próprio trabalho que exercem profissionalmente ou a atividades de lazer, ócio, ou, ainda, a seus relacionamentos sociais e afetivos), no sentido de atender aspectos tão ou mais importantes ligados ao seu self. Note-se que isso é congruente com a redução do tempo de estudo extraclasse e com o aumento do tempo dedicado ao trabalho remunerado que o grupo apresenta no último ano, ambos proporcionais.

Observe-se, também, que as características das amostras de $4^{\circ}$. ano dos cursos de CC e AD são mais semelhantes em termos de idade, trabalho e tempo de estudo e que, nestes aspectos, os concluintes de EF são mais diferenciados (mais jovens, os que tendem a trabalhar menos e a estudar mais no último ano), além de serem os únicos que apresentaram médias superiores do valor da tarefa no $4^{\circ}$. ano.

Quanto ao segundo componente do valor da tarefa, o valor ou interesse intrínseco, é necessário observar que este é semelhante ao de meta intrínseca (e, da mesma forma, oposto ao de meta extrínseca), conforme a concepção dos modelos teóricos de orientação para metas de realização (Ames, 1992; Dweck \& Legget, 1988; Maeher \& Midgley, 1991; Nicholls, 1984). Embora no presente estudo não sejam apresentados dados específicos a esse respeito, nas medidas de orientação para metas obtidas no estudo anterior de Ruiz (2005 a), verificou-se que os mesmos alunos de CC obtiveram os menores escores na sub-escala Orientação para a Meta Intrínseca em relação aos colegas de $A D$ e $E F$ (especialmente no $4^{\circ}$. ano). Em contrapartida, foram os que obtiveram o maior índice na sub-escala Orientação para a Meta Extrínseca no último ano. Ademais, a correlação dos escores médios obtidos pelos estudantes de CC $\left(1^{\circ}\right.$. ano, $4^{\circ}$. ano e total) na sub-escala Valor da Tarefa com os obtidos naquele estudo na sub-escala Orientação para a Meta Extrínseca foi plena e positiva $(r=+1,00)$, enquanto com a sub-escala Orientação para a Meta Intrínseca foi plena mas negativa $(r=-1,00)$. Com isso, há indicadores de que o interesse intrínseco foi um dos componentes que influenciou negativamente o valor que os concluintes do curso de $\mathrm{CC}$ atribuíram às suas tarefas de aprendizagem.

Reforça essa tese o fato de que, no atual estudo, para esse grupo, (tanto quanto para o grupo do $4^{\circ}$. ano de $A D$ ), a questão com menor média foi a relacionada ao gosto pelos assuntos das disciplinas do curso - conteúdo tipicamente ligado à orientação intrínseca da motivação. Note-se que os estudantes de EF apresentaram resultado superior nessa questão, o que foi acompanhado de aumento na média do valor da tarefa no $4^{\circ}$ ano e o maior escore absoluto na questão relacionada à importância de entender os conteúdos das disciplinas.

Por outro lado, pode-se concluir que, ao tenderem mais à adoção da meta extrínseca, os ultimanistas de CC estão mais próximos do terceiro componente do valor da tarefao valor de utilidade.

Considerando-se, novamente, que esse é o grupo em que os alunos trabalham mais no $4^{\circ}$. ano (como os de $A D$, mas de forma inversa aos de EF do mesmo ano) e que, talvez, muitos deles já trabalhem na própria área em que estão fazendo sua graduação, isso aumentaria o valor de utilidade do curso e (ou) do diploma sem, necessariamente, aumentar 0 valor intrínseco por determinadas atividades ou disciplinas.

Esta característica de estudantes universitários foi verificada em pesquisa de Catunda, Silva e Ruiz (1999), na qual se constatou que as maiores expectativas de estudantes de um curso noturno de Administração 
estavam ligadas à obtenção de um diploma. Também foi verificada em pesquisa com professores universitários brasileiros, os quais consideraram que os alunos "valorizam excessivamente as notas e o diploma e muito menos o aprender" (Bordenave \& Pereira, 1998, p. 18). Além disso, estudo de Watt (2006) verificou que o valor de utilidade nas carreiras ligadas à Matemática tende a ser maior em estudantes do gênero masculino.

Levando-se em conta os resultados destes estudos e, ainda, que a maior média obtida na turma do $4^{\circ}$. ano de CC ocorreu na questão que diz respeito ao interesse na área de conteúdo do curso, pode-se concluir que o valor de utilidade foi um dos fatores mais positivos para sua motivação e, portanto, precisa ser mantido. Contudo, deveria ser buscado melhor equilíbrio entre a motivação instrumental e a motivação intrínseca destes e de outros universitários em condições semelhantes.

Embora não explicitamente presente no instrumento de pesquisa utilizado no estudo, o quarto e último componente do valor da tarefa - a crença sobre o custo ligado ao envolvimento nas tarefas de aprendizagem também pode ter sido responsável pelas diferenças significativas a menor observadas entre o grupo de alunos do último ano de $\mathrm{CC}$ e os outros dois do mesmo período.

Segundo Pintrich e Schunk (2002) esse componente justifica porque, em cursos que requerem muito esforço e tempo de estudo, os alunos tendem a "roubar" tempo de suas atividades de aprendizagem para dedicá-lo ao ócio, ao lazer e a encontros e atividades sociais ou esportivas. Também explicaria porque a antecipação de um fracasso pode levar o aluno a decidir não fazer ou procrastinar a realização um trabalho acadêmico. Esse pode ser o caso dos concluintes do curso de $\mathrm{CC}$, talvez exatamente por terem sentido no quarto ano (ou, de forma gradativa, do primeiro ao quarto), maior exigência de tempo e esforço o que pode estar ligado à sua percepção do nível de dificuldade das atividades de aprendizagem, bem como de sua capacidade e inteligência para realizá-las (Bzuneck, 2001b, 2003).

Nesse sentido, é recomendável que, para esse grupo de estudantes e para outros com características semelhantes, se analisem profundamente as tarefas de aprendizagem que lhes eram atribuídas e que se verifique se 0 currículo desenvolve, nos anos anteriores, as competências e habilidades que elas requerem, a fim de que possa atuar na chamada zona motivacional de desenvolvimento proximal, como sugere Brophy (1999), e não haja comprometimento de sua auto-eficácia (Bandura, 1997).

Além disso, supondo que muitos ultimanistas de CC já exercessem atividade profissional na mesma área, vale questionar se o currículo acadêmico do curso não estava defasado do currículo requerido no mundo do trabalho, pois isso poderia ter representado, para eles, uma relação custo $\mathrm{x}$ benefício desfavorável ao engajamento nas tarefas de aprendizagem, levando-os a reduzir seus esforços nas aprendizagens escolares.

Sobre a mesma questão, entretanto, também há que se ponderar que, segundo Bzuneck (2001b), são muitos os universitários que se sentem pressionados por uma norma social do grupo a não excederem aquilo que a maioria considera ser o esforço admissível. Por trás dessa norma estaria uma certa desvalorização da escolaridade, acompanhada por grande interesse por outras atividades sociais ou de lazer, e este pode ter sido o caso dos ultimanistas de $\mathrm{CC}$, a julgar pelo que foi discutido quanto ao valor de obtenção.

Em síntese, há indicadores de que pelo menos três dos quatro componentes do valor da tarefa podem ter comprometido, de forma significativa, a motivação dos participantes dos concluintes do curso de CC (e, em menor grau, dos do curso de $A D$ ): valor de obtenção ou importância, valor ou interesse intrínseco e crença sobre o custo relacionado ao envolvimento com as tarefas de aprendizagem.

Embora todos eles tenham se mostrado bastante relacionados, os indícios mais fortes apontam para um maior comprometimento do valor intrínseco, o que leva a concluir que terminaram seus cursos com menos prazer pelas suas tarefas de aprendizagem, mais voltados aos seus objetivos finais do que em aprender seus significados, além de menos dispostos a dedicar concentração e esforço para realizá-las.

\section{Considerações finais}

No momento em que as políticas educacionais no Brasil estão voltadas para oportunizar o acesso de maior número de estudantes ao ensino superior e em que a oferta de cursos (públicos e privados) nesse nível de ensino se expande, o presente estudo pretendeu contribuir para se compreender melhor uma das variáveis relacionadas à motivação no processo de ensinoaprendizagem: o valor que os próprios estudantes atribuem às suas tarefas de aprendizagem.

Conforme se discutiu, a variável em tela não só obteve resultados superiores aos de outros estudos feitos com grupos de universitários estrangeiros, como também se mostrou a principal responsável pela motivação dos alunos de três cursos ministrados em período noturno por uma instituição de ensino superior brasileira.

Este é, portanto, um dado que merece ser melhor investigado, verificando-se sua generalização em diferentes cursos e tipos de instituições de ensino do país, a fim de se poder estimular, mais eficazmente, a motivação que os alunos apresentam quando ingressam na universidade. 
Nesse sentido, como aqui se verificou, importa que as instituições e seus docentes cuidem de destacar, o mais possível, a importância e a aplicabilidade das matérias de cada uma das disciplinas de seus cursos, bem como de fazer com que os alunos percebam como os conteúdos de cada disciplina se relacionam com os das demais, sob pena de concluírem a universidade com saberes estanques e fragmentados, sentindo-se pouco capazes de utilizá-los em sua vida profissional.

Também importa que haja um empenho conjunto de dirigentes, docentes e alunos para que o valor intrínsecosinônimo de sentimentos positivos relacionados à aprendizagem e do uso de estratégias cognitivas adequadas para tanto - não seja desgastado ao longo dos anos na universidade.

\section{Referências}

Ames, C. (1992). Classrooms: goals, structures, and student motivation. Journal of Educational Psychology, 84(3), 261-271.

Bandura, A. (1997). Self-efficacy: the exercise of control. New York: W. H. Freeman.

Bordenave, J. D., \& Pereira, A. M. (1998). Estratégias de ensinoaprendizagem. (19 ed.). Petrópolis: Vozes.

Brophy, J. (1998). Motivating students to learn. New York: McGraw-Hill.

Brophy, J. (1999). Toward a model of the value aspects of motivation in education. Developing appreciation for particular learning domains and activities. Educational Psychologist, 34(2), 75-86.

Bzuneck, J. A. (2001a). A motivação do aluno: aspectos introdutórios. Em J. A. Bzuneck \& E. Boruchovitch (Orgs.), A motivação do aluno. Contribuições da psicologia contemporânea (pp. 9-36). Petrópolis: Vozes.

Bzuneck, J. A. (2001b). O esforço nas aprendizagens escolares: mais do que um problema motivacional do aluno. Revista Educação e Ensino - USF, 6(1), 7-18.

Bzuneck, J. A. (2003). Motivação de alunos em cursos superiores: sua relação com envolvimento cognitivo e crenças sobre inteligência (pp. 238). Em Anais do VI Congresso de Psicologia Escolar e Educacional - ABRAPEE, 2003, Salvador, Bahia.

Catunda, M. F. A. P., Silva, M. I. L., \& Ruiz, V. M. (1999). Formação em Administração e perspectivas de universitários (pp. 168). Em Resumos. XXIX Reunião Anual da Sociedade Brasileira de Psicologia, 1999, Campinas. São Paulo.

Dembo, M. H. (2000). Motivation and learning strategies for college success. A self-management approach. New Jersey: Lawrence Erbaum.

Dweck, C. S., \& Leggett, E. L. (1988). A social cognitive approach to motivation and personality. Psychological Review, 95(1), 256273.
Eccles, J. S., \& Wigfield, A. (2002). Motivational beliefs, values, and goals. Annual Review of Psychology, 53, 109-132.

Eklof, H. (2006). Development and validation of scores from an instrument measuring student test-taking motivation. Educational \& Psychological Measurement, 66(4), 643-656.

Garcia, T., \& Pintrich, P. R. (1995). Assessing student's motivation and learning strategies: the Motivated Strategies for Learning Questionnaire. Pôster apresentado na Reunião Anual da American Research Association, São Francisco, CA. ERIC Database

Kivinen, K. (2003). Assessing motivation and the use of learning strategies by secondary school students in three international schools. Dissertação de Mestrado, Departamento de Educação, Universidade de Tampere, Finlândia. Disponível: http://acta.uta.fi. Recuperado: 15 set. 2004.

Legault, L., Grenn-Demers, I., \& Pelletier, L. (2006). Why do high school students lack motivation in the classroom? Toward and understanding of academic amotivation and the role of social support. Journal of Educational Psychology, 98(3), 567-582.

Linnenbrink, E. A., \& Pintrich, P. R. (2002). Motivation as an enabler for academic success. School Psychology Review, 31(3), 313-327.

Maehr, M. L., \& Midgley, C. (1991). Enhancing student motivation: a scholwide approach. Educational Psychologist, 26(1), 399-427.

Nicholls, J. G. (1984). Achievement motivation: conceptions of ability, subjective experience, task choice, and performance. Psychological Review, 91(1), 328-346.

Pintrich, P. R., \& Schunk, D. H. (2002). Motivation in education. Theory, research and applications. (2 $2^{\mathrm{a}}$ ed). New Jersey: Pearson Education Inc.

Pintrich, P. R., Smith, D. A. F., Garcia, T., \& McKeachie, W. J. (1991). A Manual for the use of the Motivated Strategies for Learning Questionnaire (MSLQ). Universidade de Michigan: NCRIPTAL, Ann Arbor, Michigan.

Pintrich, P. R., Smith, D.A.F., Garcia, T. \& Mckeachie, W. J. (1993). Reliability and predictive validity of the Motivated Strategies for Learning Questionnaire (MSLQ). Educational and Psychological Measurement, 53(1), 801-813.

Powdrill, L. A., Just, H. D., Garcia, T., \& Amador, N. A. (1997). The effects of classroom perceptions on motivation: gender and ethnic differences. Disponível: http://www.edb.utexas.edu/edpreview/papers/ecpm/ecpm.html. Acesso: 20 jan. 2005.

Roeser, R. W., Eccles, J. S., \& Sameroff, A. J. (2000). Scholl as a context of early adolescent's academic and social-emotional development: A summary of research findings. Elementary School Journal, 100(5), 443-471.

Ruiz, V. M. (2005a). Aprendizagem em universitários: variáveis motivacionais. Tese de Doutorado não publicada, Centro de Ciências da Vida, Pontifícia Universidade Católica de Campinas, Campinas, São Paulo.

Ruiz, V. M. (2005b). Produção científica sobre motivação do universitário na base ERIC (1992-2002). Em G. P. Witter (Org.), Metaciência e Psicologia (pp. 93-110). Campinas: Alínea. 
Spiegel, M. R. (1976). Estatística. São Paulo: McGraw-Hill.

Watt, H. M. G. (2006). The role of motivation in gendered educational and occupational trajectories related to Maths. Educational Research and Evaluation, 12(4), 305-322.

Weiner, B. (2000). Motivation: an overview. Em A. Kazdin (Ed.), Encyclopedia of Psychology. Washington DC: New York American Psychological Association e Oxford U. Press.
Wigfield, A., \& Eccles, J. (1992). The development of achievement task values: a theoretical analysis. Developmental Review, 12, 265-310.

Wigfield, A., \& Eccles, J. (2000). Expectancy-value theory of achievement motivation. Contemporary Educational Psychology, 25(1), 68-81.

Wilcoxon, F., \& Wilcox, R. A. (1964). Some rapid approximate statistical procedures. Pearl River, NY: Lederle Laboratories.

Recebido em: 19/04/2007

Revisado em: 22/04/2008

Aprovado em: 27/08/2008

\section{Sobre a autora}

Valdete Maria Ruiz (growing@dgInet.com.br) - docente do UNIFAE - Centro Universitário das Faculdades Associadas de Ensino de São João da Boa Vista e do UNIPINHAL - Centro Regional Universitário de Espírito Santo do Pinhal. Doutora em Psicologia pela PUC-Campinas.

\section{Endereço para correspondência}

Rua José Bonifácio, 220 - Centro - 13800-060 Mogi Mirim-SP.

\section{Nota da autora}

Artigo em parte derivado da tese de doutorado Aprendizagem em universitários: variáveis motivacionais apresentada pela autora, sob orientação da Dra. Geraldina Porto Witter, à PUC-Campinas, em 2005. 